\title{
THE CONCEPT OF “DISCRETION OF THE COURT" IN LAW
}

\author{
Ekaterina S. Azarova \\ Volgograd State University, Volgograd, Russian Federation
}

\begin{abstract}
Introduction: the law enforcement activities are connected with such a measure as discretion, for the freedom of choosing one of a number of variants of solutions is enshrined in the law. The final result of the court as the law enforcement discretion of the subject of criminal proceedings is a reasoned, legal and motivated decision. However, as with any phenomenon, the criminal procedural discretion has its negative side, so the possibility of neutralizing these negative factors is directly dependent on the extent and depth not only of the theoretical but also practical understanding of regularities existing in the scope of the law enforcement discretion in criminal proceedings. The author of the paper sets the purpose of the study, which is to justify the concept of discretion of the court. Methods: the methodological framework for the study consists of the methods of historicism, systematicity, and comparative law. Results: the author's points of view proved in the paper is based on the knowledge in criminal law. Conclusions: as a result of the study it was revealed that the scope of discretion of the court is a discretionary phenomenon.
\end{abstract}

Key words: discretion of the court, evidence, evaluation of evidence, judicial discretion, inner conviction.

Citation. Azarova E.S. The Concept of "Discretion of the Court" in Law. Legal Concept, 2019, vol. 18, no. 2, pp. 69-73. (in Russian). DOI: https://doi.org/10.15688/lc.jvolsu.2019.2.10

УДК 343.1

ББК 67.408
Дата поступления статьи: 11.03.2019 Дата принятия статьи: 01.04.2019

\section{ПОНЯТИЕ «УСМОТРЕНИЕ СУДА» В ПРАВЕ}

\author{
Екатерина Сергеевна Азарова \\ Волгоградский государственный университет, г. Волгоград, Российская Федерация
}

Введение: деятельность правоохранительных органов связана с такой мерой, как усмотрение, поскольку свобода выбора одного из нескольких вариантов решений закреплена законом. Конечный результат суда как правоприменительного усмотрения субъекта уголовного процесса - это вынесение обоснованного, законного и мотивированного решения. Вместе с тем, как и любое явление, уголовно-процессуальное усмотрение имеет свою негативную сторону, поэтому возможность нейтрализации этих негативных факторов находится в прямой зависимости от степени и глубины не только теоретического, но и практического осмысления закономерностей, существующих в области применения правоприменительного усмотрения в уголовном судопроизводстве. Автором данного исследования поставлена цель исследования, состоящая в обосновании понятия усмотрения суда. Методы: методологическую основу работы составляют методы историзма, системности, сравнительно-правовой. Результаты: обоснованная в статье авторская позиция опирается на знание уголовного права. Выводы: в результате исследования выявлено, что сфера усмотрения суда представляет собой дискреционный феномен.

Ключевые слова: усмотрение суда, доказательства, оценка доказательств, судебное усмотрение, внутреннее убеждение.

Цитирование. Азарова Е. С. Понятие «усмотрение суда» в праве // Legal Concept = Правовая парадигмa. -2019. - T. 18, № 2. - C. 69-73. - DOI: https://doi.org/10.15688/lc.jvolsu.2019.2.10 


\section{Введение}

Понятие «усмотрение суда» и его пределы имеют огромное значение для уголовнопроцессуальной деятельности. Потребность рассмотрения практических вопросов применения усмотрения суда предопределена двумя группами факторов. Первая группа - исследование этой проблемы - позволит показать зависимость данного правового явления от доминирующего типа уголовно-процессуальной парадигмы и установить ее доктринально-юридическое и практическое значения. Вторая группа - это анализ основных признаков этого феномена и возможность дать определение усмотрению в суде и его алгоритмам, что особенно актуально для практической деятельности следственных и судебных органов [2, с. 4-9].

С одной стороны, даже ограниченная свобода в выборе одного из вариантов решения может привести к нарушениям законности, отрицательно повлиять на правопорядок. С другой стороны, ограничение усмотрения или полное его исключение может лишить суд возможности учета индивидуальных особенностей дела, что негативно влияет на правильность решения.

\section{Категория судебного усмотрения}

Основной вопрос состоит в том, чтобы с помощью правового эмпиризма определить должную степень и объем усмотрения суда в уголовном процессе.

Судебное усмотрение, с одной стороны, имеет большое значение при достижении основных целей судопроизводства, с другой стороны, оно несет в себе возможность избежания судебных ошибок по делу, которые зависят от реализации судом соответствующих полномочий.

Судебное усмотрение - это полномочие судьи в выборе решения, которое непосредственно строится на основе силлогизма, компонентами которого являются норма, фактические обстоятельства дела и решение, вытекающее из подведения под норму этих обстоятельств» $[4$, с. $8-15]$.

Полномочия суда на стадиях возбуждения уголовного дела и предварительного рас- следования наиболее широко представлены на предварительном досудебном производстве. Разрешение вопросов по усмотрению суда в досудебном производстве включает вопросы применения мер пресечения (п.п. 1, 2, 3 ч. 2 ст. 29 УПК РФ) и принуждения (п. 10), обеспечения гражданского иска (п.п. 3, прим. 9, 9 прим.), проведения следственных действий (п.п. 4, 5, 5 прим. бис 6, 7, 8, 11, 12).

Применяя процессуальные нормы по своему усмотрению, суд должен учитывать факторы и обстоятельства, которые не нашли своего описания в норме (ч. 4 ст. 165 УПК РФ), но важны для принятия правильного решения при санкционировании разрешения на проведение следственного действия [5, с. 54]. Все операции по проведению следственных действий в виде осмотра, обыска, выемки и ареста корреспонденции и других предметов производятся следователем для решения вопросов по использованию источников доказательств в процессе собирания доказательств по расследуемому уголовному делу. Тем самым априори данные следственные действия уже являются законными и по своей сути целесообразными. В то же время из общего алгоритма решения на проведение следственных действий, требующих разрешения суда, должен быть исключен принцип справедливости как противоречащий принципу государственного понуждения при собирании доказательств по уголовному делу. Итак, при разрешении вопроса о выборе окончательного решения суда на стадии предварительного расследования (ч. 4 ст. 165 УПК РФ) можно констатировать, что структура усмотрения суда согласно научным положениям правоприменительного усмотрения не может базироваться на тех критериях, которые выработаны на основе законности, целесообразности и справедливости, в качестве принципов такого усмотрения. Следовательно, возникают вопросы о том, возможна ли выработка алгоритма принятия решения по усмотрению суда, исходя из субъективных и объективных оснований как основы для разрешения проведения следственного действия следователем на стадии предварительного расследования; может ли эта основа в дальнейшем быть базисом для формирования института алгоритма усмотрения суда в уголовном процессе. 


\section{Теоретические основы усмотрения}

в уголовном процессе

Для разрешения этих проблем необходимо, прежде всего, изучить с помощью сравнительного анализа теоретические основы усмотрения в уголовном процессе и их аналог - практические основы усмотрения - как функционирующий элемент парадигмы по уголовному делу, что позволит путем выработки соответствующей научной методики, методов и приемов построить систему алгоритма усмотрения в уголовном судопроизводстве и сформировать структуру отдельных алгоритмов усмотрения суда на каждой из стадий уголовного процесса.

Итак, рассмотрим объективные и субъективные факторы, составляющие сущность системы усмотрения суда в уголовном процессе как в судебном, так и досудебном производстве. Важным моментом выступают правовая и научная основы правоприменительного усмотрения в уголовно-правовой сфере.

Уголовно-процессуальная деятельность подразумевает наличие относительно урегулированных законом предписаний поведения участников процесса, поэтому регулятивная роль уголовно-процессуального закона заключается, прежде всего, в определении возможных действий субъектов уголовного судопроизводства, а также вовлекаемых в него лиц. Ключом в механизме этих отношений является усмотрение суда, то есть установка на основе исследованных материалов уголовного дела в конкретной ситуации судебного разбирательства, опирающегося на систему усмотрения суда, соблюдение требований материального и процессуального права. Основными возможностями усмотрения остаются: судебное убеждение; механизм формирования и осуществления функции разрешения уголовного дела; внутреннее убеждение при оценке доказательств судом; факторы, среди которых правосознание, влияющие на процесс формирования убеждения в процессе усмотрения; процессуальные решения и порядок их формирования в качестве средства реализации усмотрения суда.

\section{Правовой аспект усмотрения}

Правовой основой усмотрения является свобода в деятельности судебного органа.
Нормативный характер свободы позволяет отграничить усмотрение суда от случаев, когда в действиях правоприменителя имеется определенная несвязанность, которая способна повлиять на принимаемый судебный акт. Можно выделить уголовно-процессуальные нормы в которых может быть предусмотрена определенная свобода [1, с. 67]. К ним относится конкретизация прав и обязанностей субъектов в уголовно-процессуальном правоотношении, то есть определение нормы права, которая будет применена к установленным судом фактическим отношениям между конкретными участниками разбирательства и разрешение вопросов, связанных со способностью лиц выступать участниками уголовно-процессуальных правоотношений, на стадиях судебного производства.

Кроме субъективных факторов, в усмотрение также входят объективные основы действующего уголовного и уголовно-процессуального законодательства. Нормы, принципы и гарантии уголовно-процессуального закона являются объективным фактором усмотрения суда. Данные явления называются «пределами усмотрения», что обусловлено их объективной составляющей реализации материального права через процессуальные основы правоприменения.

Правовые основы усмотрения суда являются объективным комплексом факторов, оказывающих влияние на судебное (судейское) усмотрение, его нормативные границы, определяемые правом и видами реализации такого усмотрения, на различных стадиях уголовного процесса.

Перечисленные субъективные и объективные факторы усмотрения тесно взаимообусловлены, взаимосвязаны и составляют общую уголовно-процессуальную структуру системы усмотрения суда в уголовном процессе. Каждая стадия уголовного процесса решает свои конкретные задачи, соответственно, на конкретной стадии установлен свой специализированный правовой режим, то есть правовой режим стадии уголовного процесса, который является основанием для формирования процессуального усмотрения суда на этой стадии. Это позволяет говорить о том, что система усмотрения суда тесно взаимосвязана с общеправовым режимом уголовно- 
го судопроизводства, особыми режимами досудебного и судебного производств (обвинительный и состязательный процессы) и специализированными режимами стадий уголовного процесса.

Следовательно, можно утверждать, что видовые категории режима уголовного судопроизводства являются основой построения и функционирования системы усмотрения суда, то есть последнее зависит от вида режима производства, категории стадии общеправового режима уголовного процесса.

В качестве вывода скажем, что уголовный процесс как общеправовой режим функционирования охватывает досудебное и судебное производство, которые являются особыми видовыми процессуальными режимами, и все категории стадий конкретных специализированных процессуальных режимов уголовного судопроизводства. Следовательно, правоприменительное усмотрение суда в уголовном процессе включает в себя все элементы процессуального усмотрения на стадиях как судебного, так и досудебного производств. К этим элементам относится разрешение процессуальных и процедурных вопросов конкретной стадии, а также принятие как промежуточных, так и итоговых правоприменительных решений.

В широком смысле процессуальное усмотрение суда характеризуется как элемент правового режима уголовного судопроизводства. В узком смысле процессуальное усмотрение суда охватывает процессуальный режим доказывания при принятии решений на стадии судебного разбирательства.

Под алгоритмом усмотрения суда на стадии судебного разбирательства понимается последовательность этапов формирования и формулирования судебного решения на основе трактовки доводов стороны обвинения и защиты по уголовному делу как итога состязательного процесса. Рассматривая проведенное исследование как продолжение темы теоретических основ усмотрения в уголовном процессе, можно сформулировать некоторые рекомендации и предложения связанные с постулатом «практика - критерий истины», когда теоретические положения критически анализируются через призму эмпиризма применения. Исследуя основы усмотрения на ста- дии возбуждения уголовного дела, можно констатировать следующие моменты применения усмотрения при отказе в возбуждении уголовного дела $[2$, с. $89 ; 3$, с. 90].

Содержание процессуального усмотрения следователя, дознавателя, должностного лица органа дознания или следствия включает в себя оценочные понятия в отношении повода и основания для возбуждения либо отказа в возбуждении уголовного дела. Пределы такого усмотрения ограничены рамками проверочно-следственных действий. Поэтому новеллой УПК могло бы быть введение соответствующей нормы устанавливающей процессуальную форму отказа в возбуждении уголовного дела. Что касается правоприменительного усмотрения следователя на стадии возбуждения уголовного дела, то под ним понимается процесс принятия решений по проведению процессуальных действий в зависимости от наличия и содержания объективных данных по проверке сообщений о преступлениях.

Изменения в разделе 7 УПК РФ требуют дальнейшей проработки, так как проведение проверочных следственных действий невозможно без субъектов таких действий. Поэтому следующей новеллой законодательства должно быть определение таких участников стадии возбуждения уголовного дела, как пострадавший, проверяемое лицо, очевидец.

Злоупотребление правоприменительным усмотрением на предварительном следствии представляет собой социально-правовое явление, в основе которого лежит форма процесса расследования (обвинительная). При этом нужно учитывать, что процессуальное усмотрение следователя связано с независимостью следователя при выборе тактики и методов проведения следствия как субъекта стороны обвинения.

Гарантией предупреждения вынесения следователем незаконных и необоснованных решений на досудебных стадиях является усмотрение суда. Под предупреждением такого деликта в уголовном процессе понимается преодоление негативного усмотрения управомоченных субъектов этих стадий путем применения усмотрения, которое основано на аналогии правоприменения и алгоритма принятия решения судом. 


\section{Выводы}

Схема усмотрения суда на стадии предварительного расследования базируется на принципах уголовного процесса, гарантии невмешательства в ход расследования, процессуальной независимости следователя и предупреждения нарушений прав подозреваемых, обвиняемых и иных участников следствия.

Исследуя порядок разрешения судом ходатайств о проведении следственных действий на досудебной стадии, можно утверждать, что усмотрение в этих случаях представляет собой вид решения на основе уголовных и уголовно-процессуальных норм права, принятого при применении вариативной оценки законности обоснования ходатайства следователем по расследуемому уголовному делу.

Сфера усмотрения суда на досудебных стадиях представляет собой дискреционный феномен, когда законные возможности следователя на проведение действий и решений оцениваются через применение алгоритма усмотрения. Усмотрение суда формируется и строится на объективных основах судебного усмотрения и субъективных началах судебного усмотрения и является тесным взаимопереплетением этих двух составляющих данного понятия.

Основой принятия решения суда является алгоритм усмотрения, общий для всего процесса в целом и включающий в себя отдельные алгоритмы усмотрения суда для каждой стадии уголовного процесса. Разработка и внедрение данного алгоритма соответствуют уголовно-процессуальной судебной парадигме состязательного процесса.
1. Аверин, А. В. Судебное правоприменение и формирование научно-правового сознания судей (проблемы теории и практики) : автореф. дис. ... д-ра юрид. наук : 12.00.01 / Аверин Александр Валентинович. - Саратов, 2004. - 49 с.

2. Азарова, Е. С. Теоретические основы правоприменительного усмотрения / Е. С. Азарова. Волгоград : Изд-во ВолГУ, 2013. - 204 с.

3. Азарова, Е. С. Теоретические основы усмотрения в уголовном процессе усмотрения / Е. С. Азарова. - Волгоград : Изд-во ВИЭСП, 2013. - 202 с.

4. Барак, А. Судейское усмотрение / А. Барак.M. : Норма, 1999. - 376 c.

5. Вопленко, Н. Н. Правоприменительная квалификация и юридическая ответственность // Вестник Волгоградского государственного университета. Серия 5, Социология. Право. Политика. - 2000. № 3. - С. $48-53$.

\section{REFERENCES}

1. Averin A.V. Judicial Enforcement and the Formation of the Scientific and Legal Consciousness of Judges: Issues of Theory and Practice: Dr. jurid. sci. abs. diss.: 12.00.01. Saratov, 2004. 49 p.

2. Azarova E.S. Theoretical Base of Law Enforcement Discretion. Volgograd, Izd-vo VolGU, 2013. 204 p.

3. Azarova E.S. Theoretical Base of Discretion in the Criminal Process of Discretion. Volgograd, Izd-vo VIESP,2013.202p.

4. Barak A. Judicial Discretion. Moscow, Norma Publ., 1999. 376 p.

5. Voplenko N.N. Law Enforcement Qualification and Legal Responsibility. Science Journal of Volgograd State University. Sociology. Law. Politics, 2000, no. 3, pp. 48-53.

\section{Information about the Author}

Ekaterina S. Azarova, Candidate of Sciences (Jurisprudence), Associate Professor, Department of Criminal Procedure and Criminalistics, Volgograd State University, Prosp. Universitetsky, 100, 400062 Volgograd, Russian Federation, aes130804@yandex.ru, https://orcid.org/0000-0001-5130-1653

\section{Информация об авторе}

Екатерина Сергеевна Азарова, кандидат юридических наук, доцент кафедры уголовного процесса и криминалистики, Волгоградский государственный университет, просп. Университетский, 100, 400062 г. Волгоград, Российская Федерация, aes130804@yandex.ru, https://orcid.org/0000$0001-5130-1653$ 